\title{
Editorial
}

\section{The Advanced Practice Nursing}

role in Latin America: Challenges,

Opportunities and Implications

for Universal Health Coverage

Silvia Helena de Bortoli Cassiani'

Keri Elizabeth Zug²

1. Regional Advisor on Nursing and Allied Health Personnel, Health Systems and Services World Health Organization / Pan American Health Organization, Washington D.C, United States of America. The authors are members of the Pan-American Health Organization. However, they are responsible for the points of view expressed in this publication, and do not act in behalf of the institution.

2. Health Systems and Services, World Health Organization/Pan American Health Organization D.C., United States of America. 
As part of the 53 ${ }^{\text {rd }}$ Directing Council, the Ministers of Health of the Member States of the Pan American Health Organization (PAHO) met together in Washington, DC the week of September 29, 2014, to discuss regional health priorities. One key area of discussion is the strategy for Universal Health Coverage (UHC), which calls increase the capacity of countries to provide high quality primary care while also promoting health services delivery that is more accessible, equitable, efficient, and of higher technical quality $(1,2)$. PAHO is prepared to support the member states in integrating UHC into their health systems, recognizing that human resources for health (HRH) play a critical role to the success of the UHC initiative.

In October 2013, PAHO released a Resolution: Human Resources for Health: Increasing Access to Qualified Health Workers in Primary Health Care-Based Health Systems, which emphasized the essential role HRH play in expanding access to quality primary care. As part of the Resolution, PAHO issued a mandate to increase the number of primary health care providers, including advanced practice nurses (3).

Unlike the United States and Canada which have depended largely on nurse practitioners and other types of advanced practice nurses (APNs) for quality primary care for decades, the licensed "advanced practice nurse" is a new concept in Latin America. The International Council of Nursing (ICN) International Nurse Practitioner/Advanced Practice Nursing Network defines APNs as "registered nurses who have acquired the expert knowledge base, complex decision-making skills, and clinical competencies for expanded practice, the characteristics of which are shaped by the context or country in which they are credentialed to practice. A master's level degree is recommended for entry level" (4).

The nursing workforce in Latin America is primarily composed of licensed professional nurses with bachelor's degrees and auxiliaries or nursing technicians, who have varying degrees of nursing education. Professional licensed nurses may elect to purse an academic master's after completing their bachelor's, but this degree best prepares nurses to function as educators or in management capacities, while auxiliaries and nursing technicians provide the majority of direct patient care (5).

The most notable exception is Brazil, where some universities offer the Professional Master's Degree in Nursing. The Professional Master's may be the closest to a regulated APN degree in Latin America to date, corresponding with the ICN definition. Nurses who opt for this degree at accredited universities take classes emphasizing leadership, autonomy in practice, and an advanced level of direct patient care (6).

Accessible, confident and highly skilled nurses can effectively support UHC initiatives through providing high quality primary-based health care to a broad population. To support this sector of $\mathrm{HRH}$, governments, health policy makers and universities must work together to establish a foundation for nurses to provide primary care, taking into account regulation, education and an expanded scope of nursing practice. Whether or not these professionals are called "advanced practice nurses," expanding 
their role and capacitating them with the tools and resources to provide comprehensive primary care services is the best way to ensure high quality care for populations that need it the most.

\section{References}

1. Pan American Health Organization. Strategy for universal health coverage: 154th Session of the Executive Committee; 2014.

2. Pan American Health Organization. Renewing primary health care in the Americas [internet]. No. 4. Integrated Health Service Delivery Networks; 2011. Available from: http://new.paho.org/hq/dmdocuments/2011/PHC_IHSD-2011Serie4.pdf.

3. Pan American Health Organization. Resolution CD 52.R13 Human resources for health: Increasing access to qualified health workers in primary health care-based health systems. $52^{\text {nd }}$ Directing Council, 65 ${ }^{\text {th }}$ Session of the Regional Committee. Washington, DC; 2013.

4. ICN, CIE. Nurse practitioner/advanced practice nurse: definition and characteristics [internet]; 2009. [Cited 2014 Sep 29]. Available from: https://acnp.org.au/sites/default/files/33/definition_of_apnnp.pdf.

5. Nigenda G, Magaña-Valladares L, Cooper K, Ruiz-Lario JA. Recent developments in public health nursing in the Americas. Int J Environ Res Public Health. 2010;(7):729-50. doi: 10.3390/ijerph7030729.

6. Silvino ZR. Ten years of professional master degree in nursing care of Fluminense Federal University. Online Brazilian Journal of Nursing [internet]. 2013 [cited 2014 Sep 29];12 Suppl:574-7. Available from: http://www.objnursing.uff.br/index.php/nursign/article/ view/4583. 